\title{
Presentation of congenital heart disease diagnosed at birth: analysis of 29,770 newborn infants
}

\author{
Lúcia F. P. Amorim,${ }^{1}$ Catarina A. B. Pires, ${ }^{2}$ Ana Maria A. Lana, ${ }^{3}$ Ângela S. Campos, ${ }^{4}$ \\ Regina A. L. P. Aguiar, ${ }^{5}$ Jacqueline Domingues Tibúrcio, ${ }^{6}$ Arminda Lúcia Siqueira, ${ }^{7}$ \\ Cleonice C. C. Mota, ${ }^{8}$ Marcos J. B. Aguiar ${ }^{9}$
}

\begin{abstract}
Objective: To estimate the prevalence rate and study the clinical presentation and associated factors of congenital heart diseases diagnosed at birth between August 1990 and December 2003, at the Maternity Unit of the Hospital das Clínicas, Universidade Federal de Minas Gerais, Brazil.
\end{abstract}

Methods: A retrospective, database driven study, part of the Latin-American collaborative study of congenital malformations. Records were reviewed on all live born (LB) and stillborn (SB) infants with congenital heart diseases diagnosed by postnatal echocardiogram or by autopsy. Data on birth weight, sex, age and parity were collected for the LB and studied for associations. The statistical analysis employed Pearson's chi-square test and multinomial logistic regression.

Results: During the period studied there were 29,770 births (28,915 LB and $855 \mathrm{SB})$. The prevalence of heart disease among the LB was $9.58: 1,000(277 / 28,915)$ while among SB the rate was $87.72: 1,000(75 / 855)$. Heart disease occurred isolated in $37.2 \%$ of LB cases and $18.7 \%$ of SB cases; was associated with anomalies of other organs and systems, but without a syndromic diagnosis in $31.4 \%$ of LB cases and $48.0 \%$ of SB cases; and in $23.1 \%$ of the LB cases and $32.0 \%$ of the SB cases the heart disease was a feature of a syndrome. Multivariate analysis demonstrated an association between heart disease and birth weight $\leq 2,500 \mathrm{~g}$ in all types of clinical presentation, between maternal age $\geq 35$ years and heart disease in syndromic heart disease and between female sex and isolated heart disease.

Conclusions: It was found a high prevalence, which is an alert to the medical significance of heart disease. There was association between birth weight $\leq 2,500 \mathrm{~g}$ and all forms of presentation, between increased maternal age and syndromic heart disease besides between female sex and isolated congenital heart disease.

J Pediatr (Rio J). 2008;84(1):83-90: Congenital heart disease, prevalence, abnormalities, etiology.

\section{Introduction}

It is estimated that one in every 20 live births (LB) presents some type of genetic disease and that one in every 33 exhibits a severe defect at birth. These diseases will be responsible for deaths during the first year of life, hospitalizations and high financial and emotional costs. In countries where infant mortality rates are low, congenital malformations are the primary cause of infant mortality. ${ }^{1-4}$ Since 2001

1. Médica pediatra. Mestre, Faculdade de Medicina, Universidade Federal de Minas Gerais (UFMG), Belo Horizonte, MG, Brazil.

2. Médica especialista em pediatria. Residente de Neonatologia, Hospital das Clínicas, UFMG, Belo Horizonte, MG, Brazil.

3. Doutora. Professora adjunta, Departamento de Anatomia Patológica, Faculdade de Medicina, UFMG, Belo Horizonte, MG, Brazil.

4. Médica especialista em pediatria (neonatologia), Hospital das Clínicas, UFMG, Belo Horizonte, MG, Brazil.

5. Doutora. Professora adjunta, Departamento de Ginecologia e Obstetrícia, Faculdade de Medicina, UFMG, Belo Horizonte, MG, Brazil.

6. Estatística.

7. Doutora. Professora, Departamento de Estatística, Instituto de Ciências Exatas, UFMG, Belo Horizonte, MG, Brazil.

8. Doutora. Professora associada, Departamento de Pediatria, Faculdade de Medicina, UFMG, Belo Horizonte, MG, Brazil.

9. Doutor. Professor associado, Departamento de Pediatria, Faculdade de Medicina, UFMG, Belo Horizonte, MG, Brazil.

No conflicts of interest declared concerning the publication of this article.

Suggested citation: Amorim LF, Pires CA, Lana AM, Campos AS, Aguiar RA, Tibúrcio JD, et al. Presentation of congenital heart disease diagnosed at birth: analysis of 29,770 newborn infants. J Pediatr (Rio J). 2008;84(1):83-90.

Manuscript received Sep 28 2007, accepted for publication Nov 062007.

doi:10.2223/JPED.1747 
congenital anomalies have been the second cause of deaths of children under 1 year old in Brazil, according to the Mortality Information System (MIS) maintained by the Brazilian Ministry of Health, as well is in the Metropolitan Region of Belo Horizonte, MG, Brazil. 5

Cardiac anomalies, defined as structural abnormalities of the heart or intrathoracic vessels, taking all the different anatomic forms together, are some of the most common congenital anomalies at birth. It is estimated that between two and 10 in every 1,000 LB are affected by some type of cardiac malformation. 6,7 One third of those affected have critical cardiac malformations, defined as those that require immediate investigation and treatment, or those that will lead to death during the first year of life. As medicine has advanced and early detection become possible, many of these newborn will survive and contribute to increase the population of adults with congenital heart disease. ${ }^{7-10}$

Cardiac anomalies may be presented in several ways: isolated ( 80 to $85 \%$ ), as part of a chromosomal syndrome ( 5 to $10 \%$ ) or a genetic one ( 3 to $5 \%$ ), as a well-established or occasional association with other conditions, as a result of environmental factors, infectious or otherwise, in entities recognized as ruptures. When occurring as an isolated way, heredity is, in the majority of cases, multifactorial or polygenic. Hundreds of different genes have been proposed as candidates genes, i.e. as genes that predispose to the development of a range of types of heart disease. ${ }^{11-13}$

Knowledge of the prevalence of congenital heart disease and the main factors associated with them has an important role to play in their prevention and treatment and in improving the quality of life of those affected, especially when it is expected that their prevalence will increase, as is the case in Brazil. Nevertheless, a search of the databases MEDLINE and LILACS returned few studies on the subject that had been undertaken in Brazil, and so the prevalence of congenital heart disease among our patients has not yet been well established. ${ }^{14-16}$ This study aims to contribute to that knowledge, investigating the prevalence of heart disease at a public university hospital in 29,770 consecutive deliveries over a 13-year period.

\section{Objectives}

To determine the prevalence of congenital heart disease diagnosed at birth among LB and stillborn (SB) infants; to describe its most common clinical presentations and to investigate, among the LB, any associations with birth weight, sex, age and parity, at the Maternity unit of the Hospital das Clínicas, Universidade Federal de Minas Gerais (UFMG), Brazil, between August 1990 and December 2003.

\section{Methods}

This was a retrospective, observational study, based on the database created when the Maternity Unit at the Hospital das Clínicas at UFMG joined the Latin-American collaborative study of congenital malformations (ECLAMC), starting in August 1990. This database contains records of all LB and SB born with congenital anomalies. ${ }^{17,18}$ The Hospital das Clínicas is a public university hospital that provides care on the Brazilian National Health Service (SUS - Sistema Único de Saúde).

Information on all of the LB or SB born with malformations was collected relating to morphological description of the malformation, autopsy details, results of supplementary tests, morbid events during pregnancy, family history of congenital malformations, parental consanguinity, sex and birth weight, multiple births, parity and maternal age, type of delivery, presentation and socioeconomic factors. For purposes of reference, each malformed LB was paired with a control, defined as the next LB of the same sex born without malformations. The same data were collected for each control LB. The SB were not paired with controls.

At the end of each month a report was produced listing the births, numbers of LB and SB, and broken down by sex, birth weight grouped in $500 \mathrm{~g}$ categories, maternal age classified in age groups of 5 years and parity. The report also detailed the frequency, sex and types of multiple births.

The monthly reports were analyzed in order to obtain the total numbers of LB and SB over the period and data on sex, weight, parity and maternal age for all of the infants born during the period.

The study included all LB and SB with a diagnosis of congenital heart disease at birth, confirmed by postnatal Doppler echocardiography, carried out by the pediatric and fetal echocardiography team at the Hospital das Clínicas. The study also included those SB and neonatal deaths where heart disease could be confirmed from autopsy data.

The heart diseases identified were then classified as: isolated, when the cardiac defect was the only finding; associated with malformations of other organs and systems without a syndromic diagnosis; components of chromosomal or genetic syndromes; components of ruptures and other forms not covered by the preceding categories. The heart diseases were further classified as single anomalies, where there was just one cardiac defect, or as multiple ones, where more than one cardiac defect was present.

The results of obstetric ultrasound, fetal Doppler echocardiography and postnatal Doppler echocardiography were studied, together with the autopsy data.

Newborn infants were excluded if their mothers had not given consent for their inclusion, they had patent ductus arteriosus (PDA) associated with prematurity or if Doppler echocardiogram or autopsy results were not available. 
For the purposes of statistical analysis, all 1,853 LB in the ECLAMC database with no congenital malformation whatsoever were defined as controls (controls for all those with malformations).

Pearson's chi-square test, available in the program EpiInfo 6.0, was used to test for associations between the presence of congenital heart disease and sex, birth weight, parity and maternal age. In order to test whether these associations were present in all of the forms of clinical presentation of heart disease, multivariate analysis was carried out using multinomial logistic regression with the aid of the software Minitab 14. The cutoff for statistical significance was set at $5 \%(p<0.05)$.

Statistical analyses were not carried out for the SB due to the absence of controls.

The study was approved by the Research Ethics Committee of the UFMG, hearing number ETIC 305/04.

\section{Results}

During the period between August 1st, 1990 and December 31st, 2003, there were 29,770 deliveries at the Maternity Unit of the Hospital das Clínicas at UFMG: 28,915 LB and 855 SB. A total of 352 cases of congenital heart disease were identified, with a prevalence of $11.82 \%$ births. One SB with fetal ultrasound describing a cardiac anomaly, but no autopsy was excluded, and 12 LB with clinical diagnose of heart disease, but without confirmation by postnatal echocardiogram or autopsy findings were also excluded. The parents or guardians of all of the newborn infants with heart disease gave permission for them to be enrolled on the ECLAMC study.

Of the LB, 277 exhibited heart disease, with a prevalence of $9.58 \%$, while 75 of the SB had heart disease, at a prevalence of $87.72 \%$ o SB.

From the 277 LB with heart disease, 103 (37.2\%) had isolated heart diseases; in $87(31.4 \%)$ they were associated with malformations of other organs and systems without a syndromic diagnosis; and in $64(23.1 \%)$ heart disease was a feature of a syndrome of multiple anomalies. There were also nine cases (3.2\%) of hypertrophic myocardiopathy, four cases $(1.4 \%)$ that were part of ruptures (two associated with rubella, one with toxoplasmosis and one with amniotic bands), four cases $(1.4 \%)$ of complete atrioventricular block (CAVB) without structural anomalies, three $(1.1 \%)$ of rhabdomyoma and three $(1.1 \%)$ of heart disease in combination with imperfect twinning.

Of the 103 cases in which heart disease presented as an isolated anomaly, $38(36.9 \%)$ patients had a single defect and $65(63.1 \%)$ had multiple defects.

There were 87 cases in which heart diseases were associated with anomalies of other organs and systems, but where no diagnosis of a syndrome had been established. The organs and systems most frequently affected in this group were the genitourinary system (48.3\%) and the central nervous system $(45.9 \%)$. The majority of these LB had more than one malformed organ or system. The VACTERL association (vertebral defects, imperforate anus, cardiac defects, esophageal atresia with or without tracheoesophageal fistula and defects of the renal system and of the limbs) was identified in seven cases $(8.0 \%)$, and the CHARGE association (colobomas, heart disease, choanal atresia, retardation of growth and development, genital anomalies and ear malformations and hearing disorders) was identified in two cases (2.3\%).

Of the 64 cases in which heart disease was a feature of a syndrome, 31 (48.4\%) patients had Down Syndrome, 28 of whom had septal defects, 12 of which were atrioventricular septal defects. Sixteen ( $25 \%$ ) had trisomy of chromosome 18 and three $(4.7 \%)$ had trisomy of chromosome 13 . One of the remaining 14 cases $(21.9 \%$ ) had Turner syndrome and 13 had other chromosomal or genetic syndromes.

There were 75 SB with heart disease and in 36 (48\%) of these cases heart disease was associated with anomalies of other organs and systems without a syndrome being diagnosed, in 24 (32\%) cases heart disease was a feature of a syndrome of multiple anomalies, in $14(18.7 \%)$ heart disease presented as an isolated anomaly and in one case (1.3\%) heart disease was a component of a rupture (amniotic bands).

There were 36 cases in which heart disease was associated with malformations of other organs and systems, without any diagnosis of a syndrome, and among these, the organs and systems most frequently involved were the osteomuscu$\operatorname{lar}(52.8 \%)$, genitourinary $(52.8 \%)$ and central nervous systems $(41.7 \%)$. Heart disease with malformations of more than one system or organ was also common among the SB.

Of the 24 cases in which heart disease was part of a syndrome of multiple anomalies, 13 (54.2\%) had trisomy of chromosome 18, all with multiple cardiac defects. Trisomy 21 was identified in six cases (25\%), and trisomy 13 in one case $(4.2 \%)$; one of the four remaining cases $(16.7 \%)$ had Turner syndrome and three had other chromosomal or genetic syndromes.

Heart disease presented as an isolated anomaly in 14 of the SB (18.7\%), three with single defects and 11 with multiple defects.

When all clinical presentations of heart diseases were analyzed together, atrial septal defect (ASD), ventricular septal defect (VSD) and patent ductus arteriosus (PDA) accounted for $62.6 \%$ of all defects identified, being most prevalent both among the LB (63.5\%) and among the SB (58\%). Table 1 lists the heart diseases observed in the sample of LB and SB.

It can be observed in Table 2 that, among the LB, the univariate analysis indicated associations between heart disease and birth weight $\leq 2,500 \mathrm{~g}(\mathrm{p}<0.0001)$, with an odds ratio (OR) of $5.19(95 \% \mathrm{CI} 3.92<\mathrm{OR}<6.87)$, with maternal age $\geq 35$ years $(p<0.05)$ with an OR of $1.60(95 \%$ CI $1.10<$ 
Table 1 - Number of occurrences of different heart diseases among live births and stillborn infants

\begin{tabular}{|c|c|c|}
\hline & Live births & Stillborn \\
\hline ASD & 109 & 12 \\
\hline VSD & 92 & 22 \\
\hline PDA & 94 & 17 \\
\hline $\mathrm{PS} / \mathrm{PA}$ & 37 & 5 \\
\hline TD/TA & 20 & 2 \\
\hline AVSD & 20 & 2 \\
\hline HLV & 14 & 2 \\
\hline Hypertrophic myocardiopathy & 11 & 0 \\
\hline Tetralogy of Fallot & 10 & 1 \\
\hline TGA & 9 & 2 \\
\hline $\mathrm{AH} / \mathrm{Ac} / \mathrm{IAA}$ & 4 & 6 \\
\hline AoOV+VSD & 5 & 4 \\
\hline Dextrocardia & 7 & 1 \\
\hline CAVB & 6 & 0 \\
\hline HRV & 5 & 0 \\
\hline Ectopia cordis & 4 & 1 \\
\hline Multiple anomalies & 3 & 1 \\
\hline DORV & 2 & 2 \\
\hline Rhabdomyoma & 3 & 0 \\
\hline Ebstein's anomaly & 2 & 1 \\
\hline PAVC & 2 & 1 \\
\hline Truncus arteriosus & 2 & 1 \\
\hline Univentricular atrioventricular connection & 3 & 1 \\
\hline Common atrium & 0 & 2 \\
\hline Bicuspid aorta valve & 1 & 0 \\
\hline РАНурор & 0 & 1 \\
\hline Acardia & 0 & 1 \\
\hline
\end{tabular}

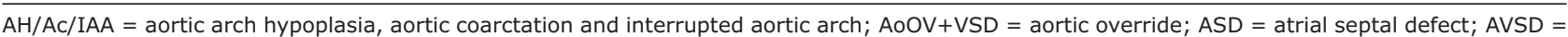
atrioventricular septal defect; $\mathrm{CAVB}=$ complete atrioventricular block; DORV = double outlet right ventricle; HLV = hypoplastic left heart; HRV = hypoplastic left ventricle; PAHypop = pulmonary artery hypoplasia; PAVC = pulmonary anomalous venous connection; PDA = patent ductus arteriosus; PS/PA = pulmonary stenosis or atresia; TD/TA = tricuspid dysplasia/atresia; TGA = transposition of the great arteries; VSD = ventricular septal defect.

OR < 2.33) and with female sex ( $<<0.05)$, with an OR of $1.40(95 \%$ CI $1.07<\mathrm{OR}<1.82)$. There was no association with maternal parity $(p=0.0743)$.

The multivariate analysis by means of multinomial logistic regression took the following categories as response variables: absence of heart disease, isolated heart disease, heart disease in association with malformations of other organs and systems, heart disease as feature of a syndrome of multiple malformations and one further group containing all other presentations observed. An association between birth weight $\leq 2,500 \mathrm{~g}$ and the presence of congenital heart disease was identified in all clinical presentation categories. 
Table 2 - Results of univariate analysis of associations between congenital heart disease and certain factors relating to the live births

\begin{tabular}{|c|c|c|c|c|}
\hline Factor & $\begin{array}{l}\text { Cardiac anomaly + } \\
\qquad n=261\end{array}$ & $\begin{array}{l}\text { Cardiac anomaly - } \\
\qquad n=1540\end{array}$ & $\begin{array}{c}\text { Total } \\
\mathrm{n}=\mathbf{2 , 1 1 4}\end{array}$ & p* \\
\hline \multicolumn{5}{|l|}{ Birth weight } \\
\hline$\leq 2,500 \mathrm{~g}$ & 134 & 313 & 447 & \\
\hline$>2,500 \mathrm{~g}$ & 127 & 1,540 & 1,667 & $\begin{array}{c}<0.0001 \\
(\mathrm{OR}=5.19,95 \% \mathrm{CI} 3.92-6.87)\end{array}$ \\
\hline \multicolumn{5}{|l|}{ Maternal age } \\
\hline$\geq 35$ years & 42 & 198 & 240 & \\
\hline$<35$ years & 219 & 1,655 & 1,874 & $\begin{array}{c}<0.05 \\
(\mathrm{OR}=1.60,95 \% \mathrm{CI} 1.10-2.33)\end{array}$ \\
\hline \multicolumn{5}{|l|}{ Sex } \\
\hline Female & 140 & 840 & 980 & \\
\hline Male & 121 & 1,013 & 1,134 & $\begin{array}{c}<0.05 \\
(\mathrm{OR}=1.40,95 \% \mathrm{CI} 1.07-1.82)\end{array}$ \\
\hline
\end{tabular}

$95 \% \mathrm{CI}=95 \%$ confidence interval; OR = odds ratio.

Eleven cases excluded with cardiac anomaly and intersex conditions, four where the mother's age had not been recorded and one case where parity had not been recorded.

* Pearson's chi-square test.

Maternal age $\geq 35$ years was associated with the presence of heart disease only when this was feature of a syndrome. An association was detected between female sex and heart disease only in isolated heart disease (Table 3 ).

\section{Discussion}

As congenital malformations become progressively more important in the etiology of infant mortality, it is indispensable to acquire knowledge of the prevalence of the most frequent types. Heart diseases are the congenital anomalies with greatest prevalence at birth. ${ }^{5,6,13,16,19}$ Early diagnosis is often necessary so that families can be informed and viable therapeutic measures planned. Many heart diseases, and the syndromes of which they are part, are incompatible with extrauterine life, what must be taken into account when the immediate care needed by those affected is considered. ${ }^{19,20}$ Despite this, we found few studies containing data from Brazil, ${ }^{14-16}$ and none of them allow for comparisons with this study due to period of diagnosis and methodologies used.

This study may have underestimated the prevalence of some types of heart disease which, due to their clinical characteristics, may not have symptoms or signs at birth. On the other hand, the inclusion of only those newborn infants whose diagnosis was confirmed by Doppler echocardiography or autopsy reduced the number of false-positive diagnoses that may have occurred if the diagnosis had been exclusively clinical. $^{8}$

The prevalence observed, both among the LB and the SB, although high, is compatible with those described in the literature. $1,2,6,7,10,12,13,21-25$ One aspect that may have contributed to the high prevalence of heart disease in this study in comparison with others is that termination of pregnancies when fetal malformations are diagnosed, is illegal in our country, but permitted in many others.

Termination of pregnancies after diagnosis of fetal anomalies may also be responsible for slight discrepancies in the relative prevalence of isolated heart diseases, when compared with those associated with dysmorphic syndromes or with anomalies of other organs and systems.

The distribution of clinical presentations of heart disease was different among the LB, in whom isolated forms predominated, and among the SB, in whom forms associated with anomalies of other organs and systems and with dysmorphic syndromes predominated. This has been described in the literature ${ }^{26-28}$ and call attention to the need to take into account the age of diagnosis to evaluate the prevalence of the different clinical presentations and their etiologies.

Among heart diseases that were feature of syndromes, the higher prevalence of chromosomal diseases was noticeable, in particular forms of aneuploidy, $82.8 \%$ among the LB and $87.5 \%$ among the SB. Although high prevalence rates of chromosomal diseases among LB with heart disease and multiple anomalies have been described in the literature, ${ }^{10-12,19,20}$ the percentages observed in this study were very much higher. A variety of factors may have contributed to this: termination of pregnancies after diagnosis of chromosomal anomalies in other countries, the time of diagnosis and the fact that this study was undertaken at a hospital that is a referral center for 
Table 3 - Results of multivariate analysis by multinomial logistic regression with clinical presentation of heart disease among live births as response variable

\begin{tabular}{|c|c|c|c|}
\hline Variable/Clinical presentation of heart disease & $\mathbf{p}$ & Odds ratio & $95 \% \mathrm{CI}$ \\
\hline \multicolumn{4}{|l|}{ Birth weight $(\leq 2,500$ and $>2,500 \mathrm{~g})$} \\
\hline Isolated & $<0.0001$ & 2.78 & $1.81-4.24$ \\
\hline Associated with malformations of other organs and systems & $<0.0001$ & 6.42 & $4.03-10.23$ \\
\hline As a feature of syndromes & $<0.0001$ & 11.14 & $6.26-19.83$ \\
\hline Other presentations & $<0.0001$ & 5.39 & $2.35-12.38$ \\
\hline \multicolumn{4}{|l|}{ Sex (female and male) } \\
\hline Isolated & 0.044 & 1.52 & $1.01-2.29$ \\
\hline Associated with malformations of other organs and systems & 0.856 & 0.96 & $0.60-1.52$ \\
\hline As a feature of syndromes & 0.408 & 1.26 & $0.73-2.17$ \\
\hline Other presentations & 0.730 & 1.16 & $0.50-2.66$ \\
\hline \multicolumn{4}{|l|}{ Maternal age ( $\geq 35$ and $<35$ years) } \\
\hline Isolated & 0.826 & 1.07 & $0.57-2.02$ \\
\hline Associated with malformations of other organs and systems & 0.373 & 0.67 & $0.28-1.60$ \\
\hline As a feature of syndromes & $<0.0001$ & 3.85 & $2.10-7.05$ \\
\hline Other presentations & 0.420 & 1.58 & $0.52-4.83$ \\
\hline \multicolumn{4}{|l|}{ Maternal parity ( 1 pregnancy and $>1$ pregnancy) } \\
\hline Isolated & 0.328 & 1.24 & $0.81-1.90$ \\
\hline Associated with malformations of other organs and systems & 0.574 & 1.15 & $0.71-1.85$ \\
\hline As a feature of syndromes & 0.169 & 1.54 & $0.83-2.86$ \\
\hline Other presentations & 0.352 & 1.54 & $0.62-3.85$ \\
\hline
\end{tabular}

$95 \% \mathrm{CI}=95 \%$ confidence interval; OR $=$ odds ratio.

Eleven cases excluded with cardiac anomaly and intersex conditions, four where the mother's age had not been recorded and one case where parity had not been recorded.

fetal diseases. The high prevalence of chromosomal diseases reinforces the recommendation to perform chromosome studies of all LB or SB with multiple anomalies.

The most common chromosomal syndrome among the LB was Down Syndrome, and atrioventricular septal defect was present in $38.7 \%$ of these patients, in agreement with what is described in the literature. ${ }^{11-13}$ Among the SB, 18 trisomy was the most common syndrome, in agreement with current knowledge of the severity of this trisomy. ${ }^{12}$ It is possible that other genetic syndromes may have been underestimated, since many of them can only be diagnosed later, because recognition of dysmorphic parameters is difficult at this age, or because their diagnoses depends on procedures not yet generally available in our setting, such as microdeletion assays and molecular studies.

The most common anatomic defects, both among LB and among SB, were ASD, VSD and PDA, in agreement with the literature. ${ }^{12,21,23,26-28}$

The univariate analysis detected an association between presence of congenital heart disease and birth weight $\leq 2,500$ $\mathrm{g}$, which has also been described in the literature. ${ }^{29-31}$ This finding was upheld by the multivariate analysis. However, the multivariate analysis provided important additional information on the associations with maternal age and sex of infant. 
The association with maternal age $\geq 35$ years, described in the literature, ${ }^{6}$ was only sustained when heart disease was a feature of a syndrome. The association with other clinical presentations, found in the univariate analysis and in the literature, might reflect the weight of the syndromic heart diseases, especially the chromosomal ones, on the whole group of heart diseases, since it is well known that increased maternal age is a risk factor for numerical chromosomal diseases, especially Down syndrome.

A similar effect was observed in the association with sex. When the whole group of clinical presentations were studied together, the univariate analysis detected that they were associated with female sex. According to the multivariate analysis, this association was only sustained in isolated heart disease. It has been well-established in the literature that isolated heart diseases, are heterogeneous from the etiologic perspective, with prevalence of the multifactorial inheritance. In this type of inheritance it is common for prevalence to be higher in one sex. This type of association may also reflect the high prevalence of PDA, which is known to be more frequent among females. ${ }^{11-13,32}$

The results of this study provide information that is important to the study of heart diseases in our country. It has demonstrated that the prevalence and presentation of congenital heart diseases are similar in our country to those observed in more developed countries, which is an alert that the health system must be prepared to diagnose and treat these patients earlier, reducing later economic costs due to the possible sequelae and the emotional suffering of those affected, and their families. In order to obtain more accurate conclusions, further, similar works are needed involving larger and more diverse samples. If one considers that congenital anomalies are already the second cause of mortality during the first year of life in our country, and that their relative importance will tend to grow, it becomes even more important to meet this challenge.

\section{References}

1. Stewart DL, Hersh JH. The impact of major congenital malformations on mortality in a neonatal care unit. J Ky Med Assoc. 1995;93:329-32.

2. Anderson RN, Smith BL. Deaths: leading causes for 2001. National Vital Statistics Reports. 2003;52:1-86.

3. Stevenson DA, Carey JC. Contribution of malformations and genetic disorders to mortality in a children's hospital. Am J Med Genet A. 2004;126:393-7.

4. Pinar H. Postmortem findings in term neonates. Semin Neonatol. 2004;9:289-302.

5. Brasil, Ministério da Saúde, MS/SVS/DASIS. Sistema de informações sobre mortalidade (SIM). http:// tabnet.datasus.gov.br. Access em: 23 /06/2006.

6. Hoffman JI, Kaplan S. The incidence of congenital heart disease. J Am Coll Cardiol. 2002;39:1890-900.
7. Gillum RF. Epidemiology of congenital heart disease in the United States. Am Heart J. 1994;127(4 Pt 1):919-27.

8. Kuehl KS, Loffredo CA, Ferencz C. Failure to diagnose congenital heart disease in infancy. Pediatrics. 1999;103(4 Pt 1):743-7.

9. Samanek KM, Goetzova J, Benesova D. Causes of death in neonates born with a heart malformation. Int J Cardiol. 1986; 11:63-74.

10. Petersen S, Peto V, Rayner M. Congenital heart diseases statistics [site in Internet]. British Heart Foundation Statistcs Database. www.heartstats.org. Access em: 23/06/2006.

11. Nora JJ. Multifactorial inheritance hypothesis for the etiology of congenital heart diseases. The genetic-environmental interaction. Circulation. 1968;38:604-17.

12. Aracena AM. Cardiopatias congênitas y síndromes malformativos genéticos. Rev Chil Pediatr. 2003;74:426-31.

13. Brennan $P$, Young ID. Congenital heart malformations: aetiology and associations. Semin Neonatol. 2001;6:17-25.

14. Guitti JC. Epidemiological characteristics of congenital heart diseases in Londrina, Paraná South Brazil. Arq Bras Cardiol. 2000:74:400-4.

15. Hagemann LL, Zielinsky P. Rastreamento populacional de anormalidades fetais por ecocardiografia pré-natal em gestações de baixo risco no município de Porto Alegre. Arq Bras Cardiol. 2004;82:313-9.

16. Miyague NI, Cardoso SM, Meyer F, Ultramari FT, Araújo FH, Rozkowisk $\mathrm{T}$, et al. Epidemiological study of congenital heart defects in children and adolescents: analysis of 4,538 cases. Arq Bras Cardiol. 2003;80:274-8.

17. Castilla EE, Orioli IM. ECLAMC: The Latin-American collaborative study of congenital malformations. Community Genet. 2004; 7:76-94.

18. Aguiar MJ, Campos AS, Aguiar RA, Lana AM, Magalhães RL, Babeto LT. Defeitos de fechamento do tubo neural e fatores associados em recém-nascidos vivos e natimortos. J Pediatr (Rio J). 2003;79:129-34.

19. Winter RM, Knowles SA, Bieber FR, Baraitser M. The malformed fetus and stillbirth. A diagnostic approach. Chichester: John Wiley; 1989.

20. Riopel DA. The heart. In: Stevenson RE, Hall JG, Goodman RM. Human malformations and related anomalies. New York: Oxford University; 1993. p. 237-53.

21. Manetti A, Pollini I, Cecchi F, De Simone L, Cianciulli D, Carbone $C$, et al. Epidemiologia delle malformazioni cardiovascolari. III. Prevalenza e decorso in 46.895 nati vivi alla Maternitá Di Careggi, Firenze, nel periodo 1975-1984. G Ital Cardiol. 1993;23:145-52.

22. Calzolari E, Garani G, Cocchi G, Magnani C, Rivieri F, Neville A, et al. Congenital heart defects: 15 years of experience of the Emilia-Romagna Registry (Italy). Eur J Epidemiol. 2003; 18:77380.

23. Pradat $P$, Francannet $C$, Harris JA, Robert E. The epidemiology of cardiovascular defects, part I: a study based on data from three large registries of congenital malformations. Pediatr Cardiol. 2003;24:195-221.

24. Jullian $M$, Karrú O. Defectos congénitos extra cardíacos asociados a malformaciones cardíacas. Rev Chil Pediatr. 1986;57:430-3.

25. Mota CC, Oliveira EC, Horta MG. Cardiopatias congênitas. In: Leão E, Corrêa EJ, Viana MB, Mota JA. Pediatria ambulatorial. 4a ed. Belo Horizonte: COOPMED; 2005. p. 721-32. 
26. Goldmuntz E. The epidemiology and genetics of congenital heart disease. Clin Perinatol. 2001;28:1-10.

27. Goetzova J, Benesova D. Congenital heart diseases at autopsy of still-born and deceased children in the Central Boehmian Region. Cor Vasa. 1981;23:8-13.

28. Tennstedt C, Chaoui R, Körner H, Dietel M. Spectrum of congenital heart defects and extracardiac malformations associated with chromosomal abnormalities: results of a seven year necropsy study. Heart. 1999;82:34-9.

29. Kramer $\mathrm{HH}$, Trampisch HJ, Rammos S, Giese A. Birth weight of children with congenital heart disease. Eur J Pediatr. 1990; 149:752-7.

30. Tanner K, Sabrine N, Wren C. Cardiovascular malformations among preterm infants. Pediatrics. 2005;116:e833-8.
31. Rosenthal GL, Wilson PD, Permutt T, Boughman JA, Ferencz C. Birth weight and cardiovascular malformations: a populationbased study. The Baltimore-Washington Infant Study. Am J Epidemiol. 1991;133:1273-81.

32. Burn J, Goodship J. Congenital heart disease. In: Rimoin DL, Connor JM, Pyeritz RE. Emery and Rimoin's principle and practice of medical genetics. 3rd ed. New York: Elsevier; 1996. p. 767828.

Correspondence:

Marcos José Burle de Aguiar

Rua Timbiras, 659/1001, Funcionários

CEP 30140-060 - Belo Horizonte, MG - Brazil

Tel. : +55 (31) 3274.3453

E-mail: aguiarmr@terra.com.br 